\title{
Webinars for a Wider Reach
}

\author{
Subhash C Parija ${ }^{1}$, Padmavathi Shanmuganathan ${ }^{2}$
}

Annals of SBV (2019): 10.5005/jp-journals-10085-8111

In this era of digitalization, there is a major paradigm shift in the recent years from a phase of seminars to webinars or online seminars. The rapid proliferation in the number of webinars is not only due to the technological advancements in communication but also due to the provision of a global platform for everyone to share their broad knowledge and accurate information to a much wider audience.

Nowadays, the usage of webinars as an online teaching modality has increased enormously due to its low cost, possibility of enrolling maximum number of participants rather than regular classroom spaces, and also easily accessible to the listeners, anywhere at any time at their convenience. But, it has its own limitations such as difficulty in gaining complete attention of the audience, inability to provide hands-on training, and hard to connect with the audience due to lack of face-to-face interaction. ${ }^{1}$

In the healthcare system, the webinars are commonly employed to educate the students, professional development of healthcare professionals, and also to disseminate healthcare information to the general public. This can be in any form, such as lectures, series of lectures, live streaming of any procedures, panel discussion, professional development programs, etc.

The strong fundamental basis for choosing a webinar over a traditional seminar is its access to larger audience with limited resources. For the grand success of a webinar, the following important factors play an essential role. They are a dedicated webinar coordination team, the theme of the webinar, webinar platform, dissemination of webinar announcement, and the potential speakers. ${ }^{2,3}$

Like any other scientific event, webinar also requires a team of dedicated people for effective coordination for the well conduct of the web event. Their primary roles are proper preplanning of the event, taking it to a larger and appropriate audience and hosting the event.

The idea of a webinar through virtual platforms is to share the comprehensive knowledge and information to the ideal participants. A proper theme selection is of utmost importance to attract a larger number of ideal participants. This can be easily arrived at by performing an analysis among the target audience for their current needs and interests.

The next crucial factor for the success of a webinar is the selection of a webinar platform for streaming it efficiently. There are many free as well as paid platforms for hosting a webinar. Each one provides different features and depending on the individual requirements to streamline a webinar, any specific virtual platform can be selected by the coordination team. Another significant step for the path of success is publicity of the event. To reach the maximum number
${ }^{1}$ Sri Balaji Vidyapeeth (Deemed to be University), Puducherry, India

${ }^{2}$ Department of Pharmacology, Mahatma Gandhi Medical College and Research Institute, Sri Balaji Vidyapeeth (Deemed to be University), Puducherry, India

Corresponding Author: Padmavathi Shanmuganathan, Department of Pharmacology, Mahatma Gandhi Medical College and Research Institute, Sri Balaji Vidyapeeth, Puducherry, India, Phone: +91 9842030490, e-mail: padmavathis@mgmcri.ac.in

How to cite this article: Parija SC, Shanmuganathan P. Webinars for a Wider Reach. Ann SBV 2019;8(2):23.

Source of support: Nil

Conflict of interest: None

of beneficiaries among the webinar-targeted group, an earlier announcement of the event with all the essential details circulated either through e-mails or social media is a must. Certain social networking services also help the webinar providers or instructors to streamline live webinars. One more vital key element that determines the success of a webinar is the choice of the potential speakers with extensive experience and knowledge. The coordination team should search and select the appropriate eminent expert/s to deliver the suitable information and share their accumulated knowledge to the perfect crowd based on their chosen theme. ${ }^{2}$

At the end of the session, make sure to get a valuable feedback of the session from all the participants to find out any faults. Avoid such mistakes in the future events and make each one a grand success. ${ }^{3}$

With this we conclude that, if all the above essential factors are taken into consideration, it's not a much complicated task for the webinar providers to conduct a successful webinar.

\section{References}

1. Burns M. Distance Education for Teacher Training: Modes, Models, and Methods. Washington, DC: Education Development Centre; 2011. Available from http://idd.edc.org/sites/idd.edc.org/files/ Distance\%20Education\%20for\%20Teacher\%20Training\%20by\%20 Mary\%20Burns\%20EDC.pdf.

2. Fadlelmola FM, Panji S, Ahmed AE, Ghouila A, Akurugu WA, Domelevo Entfellner JB, et al. Ten simple rules for organizing a webinar series. PLoS Comput Biol 2019;15(4):e1006671. DOI: 10.1371/journal. pcbi.1006671.

3. Gichora NN, Fatumo SA, Ngara MV, Chelbat N, Ramdayal K, Opap $K B$, et al. Ten simple rules for organizing a virtual conference-anywhere. PLoS Comput Biol 2010;6(2):e1000650. DOI: 10.1371/ journal.pcbi.1000650.

(c) The Author(s). 2019 Open Access This article is distributed under the terms of the Creative Commons Attribution 4.0 International License (https://creativecommons. org/licenses/by-nc/4.0/), which permits unrestricted use, distribution, and non-commercial reproduction in any medium, provided you give appropriate credit to the original author(s) and the source, provide a link to the Creative Commons license, and indicate if changes were made. The Creative Commons Public Domain Dedication waiver (http://creativecommons.org/publicdomain/zero/1.0/) applies to the data made available in this article, unless otherwise stated. 